\title{
(2) OPEN ACCESS \\ Dynamic left ventricular outflow tract obstruction in Takotsubo cardiomyopathy resulting in cardiogenic shock
}

\author{
Paulina M Conradi, Ramon B van Loon, M Louis Handoko
}

Cardiology, Amsterdam UMC, Amsterdam, Noord-Holland, The Netherlands

Correspondence to

Dr M Louis Handoko;

ml.handoko@amsterdamumc.nl

Accepted 10 March 2021

A Check for updates

(c) BMJ Publishing Group Limited 2021. Re-use permitted under CC BY-NC. No commercial re-use. See rights and permissions. Published by BMJ.

To cite: Conradi PM,

van Loon RB,

Handoko ML. BMJ Case

Rep 2021;14:e240010.

doi:10.1136/bcr-2020-

240010

\section{SUMMARY}

We report a case of a 73-year-old female patient, who was admitted to the coronary care unit due to chest pain, malaise and near syncope. During physical examination, the patient was hypotensive and there were signs of left-sided heart failure and a loud systolic murmur. Echocardiogram showed apical ballooning with dynamic left ventricular outflow tract obstruction, based on systolic anterior motion of the mitral valve with important mitral valve regurgitation. In the acute setting, the cardiogenic shock was treated cautiously with fluid resuscitation and intravenous metoprolol, resulting in direct stabilisation of her haemodynamic condition. As a codiagnosis, there was a significant stenosis of left anterior descending artery, which was treated successfully by percutaneous coronary intervention with drug eluting stents. During follow-up, left ventricular function normalised, and the left ventricular outflow tract obstruction, systolic anterior motion of mitral valve and related mitral regurgitation all resolved.

\section{BACKGROUND}

Takotsubo cardiomyopathy (TC) is an acute, reversible heart failure syndrome. The name Takotsubo is attributed to the shape of apical ballooning that resembles a Japanese octopus trap. ${ }^{1}$ This term was first described in Japan in 1990, but this syndrome was also described before and outside of Japan, only under different names. ${ }^{2}$ It mostly occurs in postmenopausal women. It seems to be triggered by sudden, unpredicted emotional or physical stress. The prevalence of TC in acute coronary syndrome (ACS) is estimated around $1 \%-2 \% .^{3}$ It mimics an ACS by typical complaints, ECG abnormalities, elevated cardiac enzymes and transient regional ventricular wall motion abnormalities (WMA). Elevated systemic levels of catecholamines and stress-related neuropeptides seem to be the underlying pathogenesis of myocardial stunning. ${ }^{4}$

Due to its reversible character, TC was believed to be a benign condition. However, patients with TC can face serious complications, such as acute heart failure and cardiogenic shock, QT-prolongation and ventricular arrhythmias. ${ }^{5}$ Complications occur in approximately $18 \%$ and burden a substantial risk of mortality. ${ }^{6}$ Cardiogenic shock is frequently caused by dynamic left ventricular outflow tract obstruction (LVOTO). ${ }^{3}$ The prevalence of LVOTO in TC is approximately $25 \%$ and its presence is determining for the treatment of shock. ${ }^{3}$ As the matter of fact, conventional therapy with inotropes and/or vasopressors, such as norepinephrine or epinephrine, may actually worsen LVOTO and can be fatal. Therefore, a fast diagnostic approach of the underlying mechanism of cardiogenic shock is of great importance. Here, we present a case of TC complicated by LVOTO and cardiogenic shock that was successfully stabilised with fluid therapy and intravenous beta-blocker.

\section{CASE PRESENTATION}

A 73-year-old female patient with prior medical history of HIV, syphilis and cerebrovascular accident, presented herself to the coronary care unit with chest pain, near syncope and malaise. Furthermore, the patient was recently exposed to greater emotional distress. At presentation, the vital parameters were: blood pressure: $82 / 53 \mathrm{~mm} \mathrm{Hg}$, pulse rate: 81 beats/min (bpm), breathing frequency: 21 / min with oxygen saturation: $94 \%$ with $3 \mathrm{~L} / \mathrm{min}$ oxygen supply. Physical examination revealed a loud holosystolic murmur and bibasilar pulmonary rales.

\section{INVESTIGATIONS}

The ECG showed diffusely subtle elevated ST segments and poor R-wave progression (figure 1). Cardiac enzymes were elevated (high-sensitive troponin T: $1380 \mathrm{ng} / \mathrm{L})$. The kidney function was impaired (estimated glomerular filtration rate: $40 \mathrm{~mL} / \mathrm{min} / 1.73 \mathrm{~m}^{2}$ ). Chest X-ray showed pulmonary congestion. Transthoracic echocardiogram (TTE) demonstrated a severe left ventricular (LV) dysfunction with a dilated and akinetic apex, whereas the basal segments were hyperdynamic with a thick basal septum. Furthermore, there was a moderate-to-severe mitral valve regurgitation (MR), as well as systolic anterior movement (SAM) of the mitral valve causing a significant LVOTO (figure 2A-C; estimated intraventricular gradient: $40 \mathrm{~mm} \mathrm{Hg}$ ). In addition, coronary angiography revealed a hemodynamically significant stenosis at mid left anterior descending (LAD) artery (fractional flow reserve: 0.75 ), as well as a significant stenosis of the first diagonal branch. In absence of clinical 'red flags' for acute myocarditis (signs and/ or symptoms of viral infection, elevated inflammatory parameters, pericardial effusion), no cardiac MRI was performed, in accordance to the 2018 InterTAK diagnostic flow chart. ${ }^{7}$

\section{DIFFERENTIAL DIAGNOSIS}

Based on the above findings, the diagnosis was cardiogenic shock due to LVOTO. TC was 


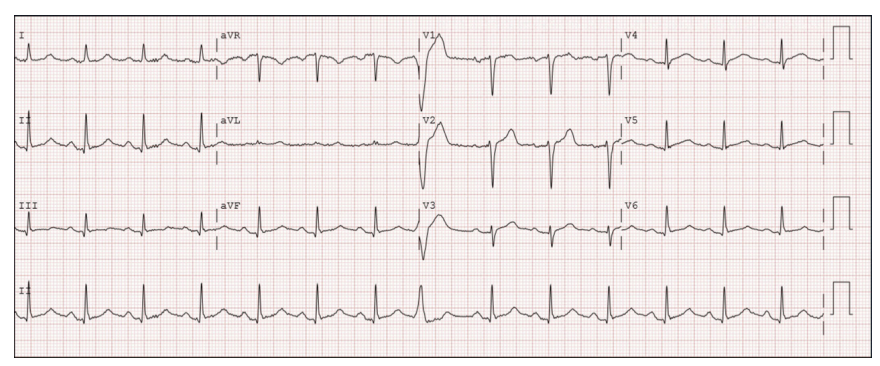

Figure 1 ECG at presentation: subtle and diffusely elevated ST segment without reciprocal depression, poor R-wave progression and borderline prolonged QTc-interval (468 ms).

perceived to be the most probable underlying cause, with a reported stressful event, an ECG without signs of transmural ischaemia and extensive WMA that could not fully explained by a (proximal) lesion of the LAD artery. For the same reasons, ACS was considered less likely. Also, there were no signs of papillary muscle rupture that might have caused acute MR and shock, neither evidence for severe aortic valve stenosis. Even though the echocardiogram displayed a thick basal septum, it did not show any other diagnostic criteria of a hypertrophic obstructive cardiomyopathy. A viral myocarditis was not likely due to an atypical anamnesis and low inflammatory parameters.

\section{TREATMENT}

In order to stabilise the patient, she was cautiously treated with $0.5 \mathrm{~L}$ in 1 hour intravenous saline fluid in order to optimise LV filling conditions, despite signs of left-sided heart failure. Although there was a modest initial rise in blood pressure, her oxygen saturation dropped despite additional oxygen supplementation, and therefore the intravenous drip was stopped. Next to volume therapy, per $1 \mathrm{mg}$ to a total of $10 \mathrm{mg}$, metoprolol was administered intravenously. The haemodynamic parameters improved with every milligram of metoprolol, as seen during

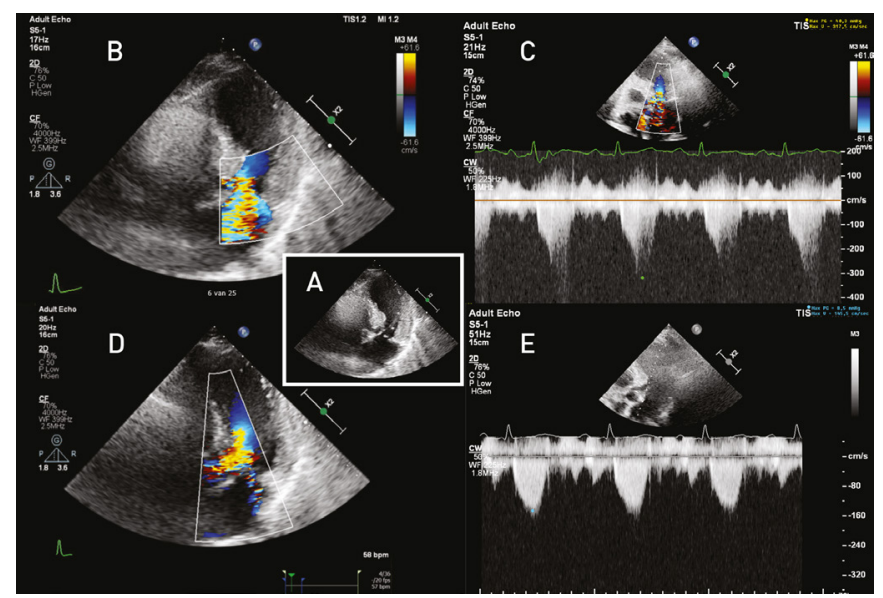

Figure 2 Transthoracic echocardiogram: apical five-chamber view. (A) (inset) apical ballooning, basal septal hypercontractility and systolic anterior movement of mitral valve. (B) Moderate-to-severe mitral valve regurgitation and left ventricular outflow tract obstruction (turbulent flow). (C) Estimated intraventricular gradient of $40 \mathrm{~mm} \mathrm{Hg}$ with a peak velocity across the left ventricular outflow tract of $3.2 \mathrm{~m} / \mathrm{s}$. (D) Immediately after intravenous beta-blocker treatment: a significant reduction in mitral valve regurgitation, in combination with (E) a drop in left ventricular outflow tract obstruction (peak velocity $1.4 \mathrm{~m} / \mathrm{s}$, estimated intraventricular gradient $<10 \mathrm{~mm} \mathrm{Hg}$ ).

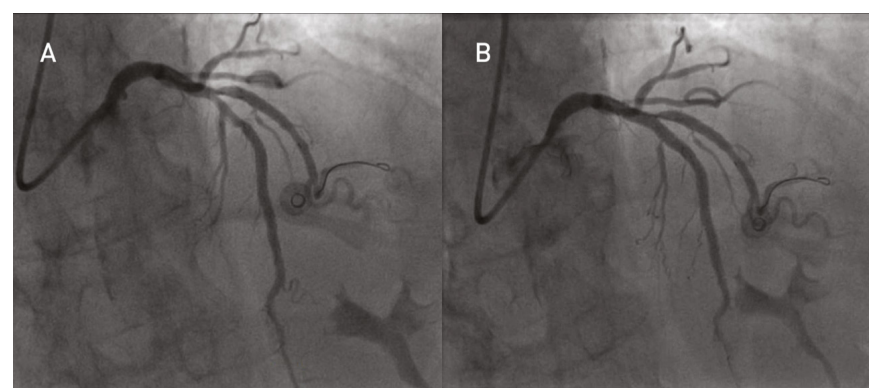

Figure 3 Coronary angiography. (A) Haemodynamically significant stenosis of mid-left anterior descending artery and first diagonal branch. (B) After stent placement with good angiographic result.

monitoring with an arterial line. Before the start of intravenous treatment with beta-blockers, the vital parameters were: blood pressure 94/47 $\mathrm{mm} \mathrm{Hg}$, pulse rate $92 \mathrm{bpm}$, oxygen saturation of $92 \%$. Within half an hour, the blood pressure increased to $129 / 63 \mathrm{~mm} \mathrm{Hg}$, the pulse rate lowered to $65 \mathrm{bpm}$, whereas oxygen saturation increased to $95 \%$. A TTE was performed directly after intravenous metoprolol treatment (figure 2D,E). LV outflow tract velocity reduced to $1.4 \mathrm{~m} / \mathrm{s}$ and the estimated intraventricular gradient dropped to $8 \mathrm{~mm} \mathrm{Hg}$. In addition, SAM and related MR resolved as well. Metoprolol $50 \mathrm{mg}$ two times per day was then continued orally. Two drug eluting stents were placed in mid-LAD with optimal result, the first diagonal branch was treated conservatively (figure 3). During hospitalisation, pharmacological treatment for heart failure and coronary artery disease (CAD) was optimised.

\section{OUTCOME AND FOLLOW-UP}

The TTE, which was repeated 2 days after start of beta-blockers, already displayed an improvement of LV function and further reduction in MR, as well as the complete disappearance of SAM. Also, subsequent ECG showed the deep negative T-waves with QT-prolonging, which fits to the natural ECG-evolution of TC (figure 4). At discharge, the QTc-interval was normalised and the negative T-waves were less prominent. Patient was discharged home in a stable cardiac condition. At 6 weeks follow-up, she was doing well and the TTE showed a good LV function with only mild MR and no signs of LVOTO. Basal septal thickness was $13 \mathrm{~mm}$. In retrospect, this may explain why the LVOTO was particularly severe in this patient.

\section{DISCUSSION}

An obstruction of the LV outflow tract is most common in hypertrophic cardiomyopathy, but also frequently seen in TC. The underlying pathophysiological mechanism is hypercontractility of the LV basal segments that leads to a Venturi-effect by

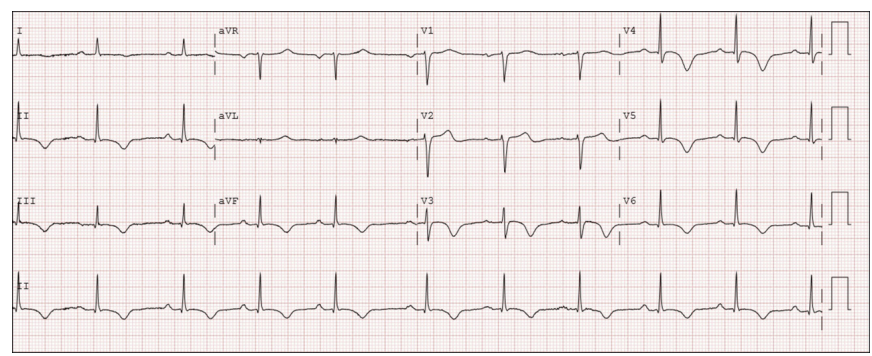

Figure 4 ECG 2 days after first presentation with deep negative Twaves and QT-prolongation (QTc: $496 \mathrm{~ms}$ ). 
systolic narrowing of the LV outflow tract with occurrence of SAM with secondary MR. Due to manifestation of LVOTO that hinders ejection, this condition is the most serious and challenging complication to manage.

With the use of TTE, this condition can be quickly diagnosed. The detection of LVOTO is important because the treatment of shock depends on the presence of LVOTO. Standard treatment of shock could even be fatal: inotropic agents may increase the LV pressure gradient due to stimulating contractility, therefore worsening of the SAM and MR, resulting in exacerbation of obstruction. ${ }^{8}$ Vasopressors, such as norepinephrine or epinephrine are also counterproductive in TC, as they are thought to further activate the catecholamine-related pathways. Vasopressin, on the other hand, increases peripheral vascular resistance using different pathways, and could be considered in this scenario. Other pharmacological agents that are indicated in acute heart failure/pulmonary oedema, such as vasodilators (eg, nitroglycerine, diuretics), are counterproductive as well, due to reduction of preload and afterload. ${ }^{7}$ Instead, LVOTO should be managed similarly to hypertrophic cardiomyopathy. Betablockers and volume therapy are indicated in order to lessen basal hypercontractility and to prolong diastole with greater end-diastolic volume. This results in widening of LVOT and therefore decreasing obstruction, elevating arterial pressure and downgrading MR, as seen in our case and of others. ${ }^{9-11}$ There are no randomised trials that back-up these measures, with only a few supporting case reports and case-controlled studies. ${ }^{9}{ }^{12} 13$ Santoro and colleagues showed that esmolol infusion in nine patients with TC and LVOTO resulted in a reduction of LVOT pressure gradient (before treatment: $48 \pm 17 \mathrm{~mm} \mathrm{Hg}$, after: $18 \pm 2 \mathrm{~mm} \mathrm{Hg} ; \mathrm{p}<0.01) .{ }^{13}$ Even though there were signs of leftsided decompensation in the form of pulmonary congestion, we carefully administered saline intravenously, which resulted in some beneficial effect on blood pressure. The ultimate bail-out measure to stabilise the cardiac condition in LVOTO would have been LV mechanical support, such as Impella. ${ }^{714}$ This was fortunately not necessary in our case, due to rapid stabilisation of the cardiac condition after fluid resuscitation and intravenous metoprolol.

Although TC is believed to be a benign condition, the longterm rates of mortality and recurrence in patients are not insignificant and resemble those of ACS. A meta-analysis of 4679 patients with TC showed an annual rate of mortality of $3.5 \%$ and a recurrence rate of $1.0 \%{ }^{15}$ However, the prognosis of shock in TC due to LVOTO seems to be favourable with the adequate treatment. ${ }^{12}$

Another interesting aspect of this case is the combined ischaemic and stress-induced origin of the cardiomyopathy. Although non-obstructive CAD is common in patients with TC, the association between TC and obstructive CAD/ACS should not be missed since ischaemia may also trigger TC. ${ }^{16}$ The coexistence of obstructive CAD in patients with TC is $15 \%$ and therefore quite frequent. ${ }^{17}$ In the current diagnostic criteria of InterTAK, obstructive $\mathrm{CAD}$ is no longer an exclusion criteria for the diagnosis of TC. ${ }^{4}$ In these patients, the diagnosis is based on the extend of regional WMA beyond the territory supplied by a single coronary artery, as well as the recovery of the cardiomyopathy within days or weeks, as in our case. Imaging techniques, like cardiac magnetic resonance could help to differentiate between TC and ACS or myocarditis, although it is less suitable in an acute setting. ${ }^{4}$ In patients with ACS and cardiomyopathy due to myocarditis, characteristic late gadolinium enhancement is seen on cardiac MRI, whereas it is mostly absent in TC. ${ }^{18}$ The clinical course and prognosis of TC and ACS display profound differences when presented with cardiogenic shock. Vallabhajosyula and colleagues demonstrated that patients in cardiogenic shock with TC received a cardiac catheterisation earlier than patients with ACS. ${ }^{19}$ Furthermore, TC was associated with higher rates of acute respiratory insufficiency, likely due to more extensive WMA and additional right ventricular dysfunction. Nevertheless, in-hospital mortality was lower in TC with cardiogenic shock compared with ACS, which might be explained by the reversible nature of TC, younger age and fewer comorbidities in these patients.

In conclusion, cardiogenic shock can be a severe complication in patients with TC, which has to be diagnosed quickly in order to choose the right treatment to rapidly stabilise this critical condition. Beta-blockers and volume therapy have a good effect on vital parameters in this precarious situation, whereas

\section{Patient's perspective}

The time I was admitted to the hospital, I was in a very stressful period of my life due to personal and family problems. On that particular day, I was Nordic Walking with my group. Quickly, I felt very exhausted. But I continued walking, even though it was difficult to keep up. After the walk I biked home, when suddenly I felt pain in the gastric area and left arm. Therefore, I went to the general practitioner. There, they advised me to take the double dosage of stomach protectors and I got discharged. But at that time my body felt really heavy, like it was drawn to the ground. My son advised me to go to the emergency room, where they took me in and did various tests. Eventually, I got transferred to the cardiac care unit. I never thought it was my heart that was the cause of my symptoms. I was surrounded by a resident and a cardiologist and they told me it was Takotsubo cardiomyopathy, the 'broken heart' syndrome. The treatment would consist of pills and resting, which sounded very magical to me. With a lot of care and close monitoring, the doctors gave me a beta-blocker and fluid infusion, which resulted in a lower heart rate. Very soon after, I felt much better and relieved. I cannot remember whether I felt scared at that moment. That fear came later, when I realised that I had a heart failure syndrome. I thought that I could never work in the garden again, but then a cardiologist told me, 'I bet you will soon be able to do it again'. I also got two stents due to a narrowed vessel. At discharge, I was scared to go home. But during revalidation, I recovered, as well did my heart function. I am happy because I do not have any complaints anymore.

\section{Learning points}

- Presentation with cardiogenic shock is a severe complication of Takotsubo cardiomyopathy that is often caused by dynamic left ventricular outflow tract obstruction. It should be diagnosed quickly due to consequences of treatment. Bedside echocardiography plays an essential role.

- In case of cardiogenic shock and presence of left ventricular outflow tract obstruction, treatment of cardiogenic shock with inotropes and most vasopressors, such as norepinephrine or epinephrine, are counterproductive. Treatment consists of beta-blockers and volume therapy, even though it may seem counterintuitive.

- Takotsubo cardiomyopathy can be accompanied by ischaemic origin of cardiomyopathy due to obstructive coronary artery disease. 
inotropes and most vasopressors may be detrimental. However, bedside echocardiographic monitoring is mandatory. The coexistence of obstructive CAD does not exclude TC as a diagnosis, but should be further investigated.

Contributors PMC and MLH were the treating doctors of the patient. PMC and MLH substantially contributed to the conception or design of the work. PMC, MLH and RBvL contributed to drafting the work or revising it critically for important intellectual content. PMC, MLH and RBvL contributed to final approval of the version to be published. PMC, MLH, RBvL contributed to agreement to be accountable for al aspects of the work in ensuring that questions related to the accuracy or integrity of any part of the work are appropriately investigated and resolve.

Funding This study was funded by Hartstichting (MLH: E.Dekker Senior Clinical Scientist (2020T058)).

Competing interests None declared.

Patient consent for publication Obtained.

Provenance and peer review Not commissioned; externally peer reviewed.

Open access This is an open access article distributed in accordance with the Creative Commons Attribution Non Commercial (CC BY-NC 4.0) license, which permits others to distribute, remix, adapt, build upon this work non-commercially, and license their derivative works on different terms, provided the original work is properly cited and the use is non-commercial. See: http://creativecommons.org/ licenses/by-nc/4.0/.

\section{REFERENCES}

1 Kurisu S, Sato H, Kawagoe T, et al. Tako-tsubo-like left ventricular dysfunction with STsegment elevation: a novel cardiac syndrome mimicking acute myocardial infarction. Am Heart J 2002;143:448-55.

2 Y-Hassan S, Yamasaki K. History of takotsubo syndrome: is the syndrome really described as a disease entity first in 1990? some inaccuracies. Int I Cardiol 2013:166:736-7.

3 El Mahmoud R, Mansencal N, Pilliére R, et al. Prevalence and characteristics of left ventricular outflow tract obstruction in Tako-Tsubo syndrome. Am Heart J 2008;156:543-8.

4 Ghadri J-R, Wittstein IS, Prasad A, et al. International expert consensus document on takotsubo syndrome (Part I): clinical characteristics, diagnostic criteria, and pathophysiology. Eur Heart J 2018;39:2032-46.
5 Pelliccia F, Kaski JC, Crea F, et al. Pathophysiology of takotsubo syndrome. Circulation 2017:135:2426-41.

6 Donohue D, Movahed M-R. Clinical characteristics, demographics and prognosis of transient left ventricular apical ballooning syndrome. Heart Fail Rev 2005;10:311-6.

7 Ghadri J-R, Wittstein IS, Prasad A, et al. International expert consensus document on takotsubo syndrome (Part II): diagnostic workup, outcome, and management. Eur Heart J 2018;39:2047-62

8 Chatterjee K, Hutchison SJ, Chou TM. Mechanical Complications of Acute Myocardial Infarction. In: Cardiac intensive care. W.B. Saunders, 2010: 233-40.

9 Obafemi T, Carline N, Khand A. Syncope and cardiogenic shock in an 80-year-old woman. BMJ Case Rep 2018;2018. doi:10.1136/bcr-2017-223924. [Epub ahead of print: 16 Feb 2018].

10 Medina de Chazal H, Del Buono MG, Keyser-Marcus L, et al. Stress Cardiomyopathy Diagnosis and Treatment: JACC State-of-the-Art Review. J Am Coll Cardiol 2018;72:1955-71.

11 Yoshioka T, Hashimoto A, Tsuchihashi K, et al. Clinical implications of midventricular obstruction and intravenous propranolol use in transient left ventricular apical ballooning (Tako-tsubo cardiomyopathy). Am Heart $J$ 2008;155:526.e1-526.e7.

12 Villareal RP, Achari A, Wilansky S, et al. Anteroapical stunning and left ventricular outflow tract obstruction. Mayo Clin Proc 2001;76:79-83.

13 Santoro F, leva R, Ferraretti A, et al. Hemodynamic effects, safety, and feasibility of intravenous esmolol infusion during takotsubo cardiomyopathy with left ventricular outflow tract obstruction: results from a multicenter registry. Cardiovasc Ther 2016;34:161-6.

14 Mohammedzein A, Taha A, Salwan A, et al. Impella use in cardiogenic shock due to takotsubo cardiomyopathy with left ventricular outflow tract obstruction. JACC Case Rep 2019;1:161-5.

15 Pelliccia F, Pasceri V, Patti G, et al. Long-Term prognosis and outcome predictors in takotsubo syndrome: a systematic review and meta-regression study. JACC Heart Fail 2019;7:143-54.

16 Y-Hassan S. Takotsubo syndrome triggered by acute coronary syndrome in a cohort of 20 patients: an often missed diagnosis. Int J Cardiol Res 2015;2:28-33.

17 Templin C, Ghadri JR, Diekmann J, et al. Clinical features and outcomes of takotsubo (stress) cardiomyopathy. N Engl J Med 2015;373:929-38.

18 Teraoka K. Clinical usefulness of cardiovascular magnetic resonance imaging in the diagnosis of takotsubo cardiomyopathy. Circ J 2012;76:814-5.

19 Vallabhajosyula S, Dunlay SM, Murphree DH. Cardiogenic shock in takotsubo cardiomyopathy versus acute myocardial infarction: an 8-year national perspective on clinical characteristics, management, and outcomes. JACC Hear Fail 2019;7:469-76.

Copyright 2021 BMJ Publishing Group. All rights reserved. For permission to reuse any of this content visit https://www.bmi.com/company/products-services/rights-and-licensing/permissions/ BMJ Case Report Fellows may re-use this article for personal use and teaching without any further permission.

Become a Fellow of BMJ Case Reports today and you can:

- Submit as many cases as you like

Enjoy fast sympathetic peer review and rapid publication of accepted articles

- Access all the published articles

Re-use any of the published material for personal use and teaching without further permission

Customer Service

If you have any further queries about your subscription, please contact our customer services team on +44 (0) 2071111105 or via email at support@bmj.com.

Visit casereports.bmj.com for more articles like this and to become a Fellow 